\title{
Exploration of Knowledge of Tuberculosis Patients Regarding their Disease in Quetta, Pakistan
}

\author{
Noman Ul Haq ${ }^{1}$, Aqeel Nasim², Palwasha Kakar ${ }^{3}$
}

${ }^{1}$ Assistant Professor, Faculty of Pharmacy \& Health Sciences, University of Balochistan, Quetta, Pakistan; ${ }^{2}$ Post Graduate [M.Phil.] Scholar, Department of Pharmacy Practice, Faculty of Pharmacy \& Health Sciences, University of Balochistan, Quetta, Pakistan; ${ }^{3}$ Post Graduate Student [Pharm-D], Faculty of Pharmacy \& Health Sciences, University of Balochistan, Quetta, Pakistan

[Received: 12 July 2020; Accepted: 30 August 2020; Published: 1 December 2020]

\begin{abstract}
Background: Knowledge of tuberculosis is very important for the patients. Objective: This study was aimed to assess and explore the knowledge of TB patients regarding their diseases in Quetta, Pakistan. Methodology: This questionnaire based, cross sectional analysis was conducted in Fatima Jinnah Chest Hospital, Quetta with in all TB patients. Knowledge was assessed by using a pre-validated self-administered questionnaire containing 22 disease related questions. Convenience sampling technique was used for data collection. Descriptive analysis was used to demonstrate the characteristics of the study population. Result: Mean age of respondents was $40.99 \pm 18.10$. Study was dominated by $168(60.00 \%)$ of females. Two hundred $(71.40 \%)$ were married. One hundred sixteen $(41.40 \%)$ had no any education. One hundred sixty-eight $(60.00 \%)$ were Pashtun. One hundred thirty-two (47.10\%) having income less than $10000 \mathrm{PKR}$ and ranges between 10000 to 18000 PKR respectively. One hundred fifty-six $(55.70 \%)$ were having rural residency. One hundred fifty-six $(58.10 \%)$ having no any co-morbidity. Mean score of knowledge was $11.23 \pm 3.616$. Conclusion: Knowledge is a key factor in understanding any particular disease. If the level of knowledge is low in some or all parts of the disease, it will actually affect the patient. It can be concluded that there is a need to raise awareness of TB symptoms, mode of transmission, prevention, diagnosis and treatment of the disease through health education. [Bangladesh Journal of Infectious Diseases, December 2020;7(2):78-83]

Keywords: Tuberculosis; knowledge; disease state knowledge

Correspondence: Aqeel Nasim, Post Graduate Student [Pharm-D], Faculty of Pharmacy \& Health Sciences, University of Balochistan, Quetta, Pakistan; Email: aqeel_nasim@yahoo.com; Cell no.: +92 3337879598

Conflict of interest: No conflict of interest

Funding agency: No funding agency

Contribution to authors: Haq NU, Nasim A involved in protocol preparation, data collection and literature search up to manuscript writing. Kakar P involved in literature search, preparation and revision of this manuscript.

How to cite this article: Haq NU, Nasim A, Kakar P. Exploration of Knowledge of Tuberculosis Patients Regarding their Disease in Quetta, Pakistan. Bangladesh J Infect Dis 2020;7(2):78-83

Copyright: (02020. Haq et al. Published by Bangladesh Journal of Infectious Diseases. This article is published under the Creative Commons CC BY-NC License (https://creativecommons.org/licenses/by-nc/4.0/). This license permits use, distribution and reproduction in any medium, provided the original work is properly cited, and is not used for commercial purposes.
\end{abstract}




\section{Introduction}

Tuberculosis is the leading infectious diseases worldwide and is responsible for the largest number of deaths in the world ${ }^{1-3}$. Tuberculosis remains main public health concern among developed and developing countries even though drugs for prevention of TB have been available for past 6 decades ${ }^{4}$.

Tuberculosis (TB) is a fatal infectious disease caused by several species of Mycobacteria, primarily Mycobacterium tuberculosis ${ }^{5}$. In 2014 statistics shown that, about 9.6 million people diagnosed with $\mathrm{TB}$ and 1.5 million expired from $\mathrm{TB}^{5}$. Over $95.0 \%$ of TB deaths happen in low- and middle-income countries, and it is among the top 5 causes of death for women aged 15 to 44 years $^{6}$. According to World Health Organization Global tuberculosis report 2015 out of 185 million population of Pakistan, the mortality rate is estimated forty-eight thousand having TB; however, prevalence of TB + HIV found six hundred and thirty thousand ${ }^{7}$.

Tuberculosis (TB), one of the oldest noted human disease, is still one of the major cause of deaths among the infectious diseases, regardless of the worldwide use of vaccines and several antibiotics. Since two million people die each year from this disease. TB has many indexes, affecting bone, the central nervous system, and many other organ systems ${ }^{8}$. TB is contagious disease triggered by the tubercle bacillus, Mycobacterium tuberculosis and characterized pathologically by inflammatory infiltration, formation of tubercles, caseation, necrosis, abscesses, fibrosis, and calcification. It commonly disturbs the respiratory system, but other parts of the body such as the gastrointestinal and genitourinary tracts, bones, joints, nervous system, lymph nodes, and skin may also become infected ${ }^{9}$.

Studies have been conducted on assessment of knowledge regarding $\mathrm{TB}^{1-4,10}$. Several studies have reported the lack of knowledge worldwide ${ }^{11-13}$. While some studies have reported the lack of knowledge of TB in Pakistan ${ }^{14-15}$. Despite TB being an issue of global concern, no studies on knowledge of TB patients regarding their disease have been reported in Quetta, Pakistan. Therefore, this study aimed to explore the knowledge of TB patients regarding their disease in Quetta.

\section{Methodology}

Study Design, Settings and Sampling: A questionnaire based, cross-sectional analysis was conducted. Registered patients from Fatima Jinnah
Chest Hospital, also called TB Sanatorium Quetta, Pakistan were included for this study. Fatima Jinnah chest hospital is major hospital for the treatment of TB all over Balochistan and patients from every district of Baluchistan came here for treatment of TB. According to registered patient data 352 questionnaires were distributed among patients of whom 280 returned the questionnaire.

Ethical Consideration: This study was performed according to National Bioethics Committee Pakistan's guidelines ${ }^{16}$. Written consent was taken from patients prior to data collection. Patients were ensured about the confidentiality of their answers and their right to leave the survey at any time.

Study Tool: The study tool was designed by experts of Department of Pharmacy Practice, Faculty of Pharmacy, University of Balochistan, Quetta, with help previous articles and WHO (World Health Organization) guideline for KAP studies for $\mathrm{TB}^{17}$. The final questionnaire comprised of four main sections, the first section is Demographics, second section comprised of Twenty-Two questions specifically to assess the knowledge regarding the disease TB, third section is Co-morbidities and fourth is Source of information. The knowledge question consists of domains i.e. General description, Etiology, Sign and Symptoms, Risk factors, Diagnosis and Prevention of TB. The dichotomous type of questionnaire was made with 'Yes' 'No' and 'Don't know' options.

Scoring Method: The response was recorded as 'Yes' 'No' and 'Don't know'. Each correct answer carried 1 mark whereas wrong or 'don't know' carried 0 mark. This gave a total score range of 0 to 22. A cut-off level of $\leq 11$ was considered as poor knowledge while >11 was regarded as good knowledge.

Statistical Analysis: Descriptive analysis of patient's demographic information was performed. Categorical variables were measured as frequency and percentages while continuous variables were expressed as mean with standard deviation. Inferential statistics (Mann-Whitney $U$ test and Kruskal Wallis tests, $\mathrm{p}<0.05)$ were used to assess the significance among study variables.

\section{Results}

Demographic characteristics: The demographic characteristics of respondents were displayed in Table 1. It describes the demographic information of the study participants. Mean age of respondents was $40.99 \pm 18.10$. Study was dominated by 168 $(60.00 \%)$ of females. Two hundred $(71.40 \%)$ were married. One hundred sixteen $(41.40 \%)$ had no any 
education. One hundred sixty-eight (60.00\%) were Pashtun. One hundred thirty-two (47.10\%) had income less than 10000 PKR and ranges between 10000 to 18000 PKR respectively. One hundred fifty-six $(55.70 \%)$ were having rural residency. One hundred fifty-six $(58.10 \%)$ had no any co-morbidity.

Association of Demographics and Knowledge Score: Inferential statistics, i.e. Mann-Whitney test and Kruskal Wallis test were applied to compare scores of knowledge with various demographic variables. Association of demographic characteristics and mean knowledge score is presented in Table 1. Mann-Whitney test $(\mathrm{p}<0.05)$ and Kruskal Wallis test $(\mathrm{p}<0.05)$. By taking $\mathrm{p}<0.05$ as statistically significant value. No statistically significant difference in scores was observed among demographic variables.

Table 1: Demographic Characteristic of the Respondents $(n=280)$

\begin{tabular}{|c|c|c|c|c|}
\hline Category & Frequency & Percent & $\begin{array}{c}\text { Knowledge Score } \\
(\text { Mean } \pm \text { SD })\end{array}$ & P value \\
\hline \multicolumn{5}{|l|}{ Age Group } \\
\hline 12 to 21 Years & 40 & 14.3 & $10.2 \pm 2.898$ & \multirow{6}{*}{0.154} \\
\hline 22 to 31 Years & 68 & 24.3 & $12.3 \pm 4.429$ & \\
\hline 32 to 41 Years & 40 & 14.3 & $9.2 \pm 3.676$ & \\
\hline 42 to 51 Years & 60 & 21.4 & $10.7 \pm 3.132$ & \\
\hline 52 to 61 Years & 28 & 10.0 & $11.4 \pm 3.409$ & \\
\hline$\geq 62$ Y ears & 44 & 15.7 & $12.9 \pm 2.737$ & \\
\hline \multicolumn{5}{|l|}{ Gender } \\
\hline Male & 112 & 40.0 & $11.4 \pm 3.773$ & \multirow{2}{*}{0.729} \\
\hline Female & 168 & 60.0 & $11.1 \pm 3.552$ & \\
\hline \multicolumn{5}{|l|}{ Marital status } \\
\hline Married & 200 & 71.4 & $11.18 \pm 1.888$ & \multirow{2}{*}{0.334} \\
\hline Unmarried & 80 & 28.6 & $12.00 \pm 6.298$ & \\
\hline \multicolumn{5}{|l|}{ Education Level } \\
\hline Matric & 44 & 15.70 & $11.57(3.749)$ & \multirow{5}{*}{0.668} \\
\hline Intermediate & 28 & 10.00 & $10.55(3.203)$ & \\
\hline Masters & 4 & 1.400 & $11.00(3.464)$ & \\
\hline Religious education only & 88 & 31.40 & $14.00(0000)$ & \\
\hline None & 116 & 41.40 & $10.50(5.260)$ & \\
\hline \multicolumn{5}{|l|}{ Income } \\
\hline$<10,000$ & 132 & 47.10 & $4.55(3.001)$ & \multirow{5}{*}{0.130} \\
\hline 10,000 to 18,000 & 132 & 47.10 & $11.12(3.830)$ & \\
\hline 18,001 to 25,000 & 8 & 2.900 & $13.50(2.121)$ & \\
\hline More than 25,000 & 4 & 1.400 & $20.00(0000)$ & \\
\hline No income & 4 & 1.400 & $4.00(00000)$ & \\
\hline \multicolumn{5}{|l|}{ Locality } \\
\hline Urban & 124 & 44.30 & $11.68(3.637)$ & \multirow[t]{2}{*}{0.243} \\
\hline Rural & 156 & 55.70 & $10.87(3.607)$ & \\
\hline
\end{tabular}

**Mann Whitney Test; * Kruskal Wallis Test

Assessment of knowledge of Tuberculosis: Table 2 describes the present level of knowledge about Tuberculosis. Each response was recorded as 'Yes' 'No' and 'Don't know'. Each correct answer carried 1 mark whereas 'No' or 'don't know' carried 0 mark. This gave a total score range of 0-22. A cut-off level of $\leq 11$ was considered as poor knowledge while $>11$ was regarded as good knowledge. Mean of total score of knowledge was $11.09 \pm 3.49$. Out of 280 respondents, $144(51.4 \%)$ had poor knowledge and $136(48.6 \%)$ had good knowledge about Tuberculosis.

Table 2: Responses related to knowledge of Tuberculosis

\begin{tabular}{|l|c|c|}
\hline Questions & Yes & No \\
\hline Have you heard about disease name TB? & $92.1 \%$ & $2.90 \%$ \\
\hline TB primarily affects lungs? & $68.6 \%$ & $31.4 \%$ \\
\hline
\end{tabular}




\begin{tabular}{|c|c|c|}
\hline TB is an infectious disease & $32.9 \%$ & $67.1 \%$ \\
\hline Is TB caused by bacteria? & $7.10 \%$ & $92.9 \%$ \\
\hline Can TB cause lungs cancer? & $11.4 \%$ & $88.6 \%$ \\
\hline Can TB cause death? & $92.9 \%$ & $7.10 \%$ \\
\hline Is excessive cough that lasts longer than three weeks a symptom of TB? & $84.3 \%$ & $15.7 \%$ \\
\hline Is excessive cough with presence of sputum symptom of TB? & $94.3 \%$ & $5.70 \%$ \\
\hline Is cough with blood a symptom of TB? & $57.1 \%$ & $42.9 \%$ \\
\hline Is there excessive weight loss without any apparent reason in TB? & $82.9 \%$ & $17.1 \%$ \\
\hline $\begin{array}{l}\text { Is fever that lost more than seven days without any clear cause or disease } \\
\text { symptom of TB? }\end{array}$ & $55.7 \%$ & $44.3 \%$ \\
\hline Is TB spread through the air when people with TB cough or sneeze? & $32.9 \%$ & $67.1 \%$ \\
\hline Is TB spread through handshakes/sharing dishes? & $12.9 \%$ & $87.1 \%$ \\
\hline Is TB spread through touching items in public place? & $20.0 \%$ & $80.0 \%$ \\
\hline Is TB spread through blood transfusion? & $12.9 \%$ & $87.1 \%$ \\
\hline Is TB spread through sexual contact? & $28.6 \%$ & $71.4 \%$ \\
\hline Is TB diagnosed by blood test? & $30.0 \%$ & $70.0 \%$ \\
\hline Is TB diagnosed by sputum test? & $94.3 \%$ & $5.70 \%$ \\
\hline Is TB curable? & $92.9 \%$ & $7.10 \%$ \\
\hline Is there any vaccine available for TB? & $17.1 \%$ & $82.9 \%$ \\
\hline Is treatment of TB is six months? & $42.9 \%$ & $57.1 \%$ \\
\hline Can TB affect other parts of body apart from lungs? & $40.0 \%$ & $60.0 \%$ \\
\hline
\end{tabular}

Sources of Information: The source of information regarding TB knowledge was presented in table 3 , it showed that dominant source of information $(n=220$, $78.5 \%$ ) was health workers through which patients seek information followed by radio as source of TB information among patients $(\mathrm{n}=124,44.2 \%)$.

Table 3: Sources of Information*

\begin{tabular}{|l|c|c|}
\hline Source of Information & Frequency & Percent \\
\hline Newspaper & 28 & 10.0 \\
\hline Radio & 124 & 44.2 \\
\hline TV & 24 & 8.6 \\
\hline Health workers & 220 & 78.5 \\
\hline Family \& neighbors & 24 & 8.6 \\
\hline $\begin{array}{l}\text { Brochures pictures \& } \\
\text { printed material }\end{array}$ & 52 & 18.6 \\
\hline Religious leaders & 12 & 4.30 \\
\hline
\end{tabular}

*More than one response is allowed to select

Association of demographics and knowledge score: Inferential statistics, i.e. Mann-Whitney test and Kruskal Wallis test were applied to compare scores of knowledge with various demographic variables. Association of demographic characteristics and mean knowledge score was presented in Table 4. Mann-Whitney test $(\mathrm{p}<0.05)$ and Kruskal Wallis test $(\mathrm{p}<0.05)$. By taking $\mathrm{p}<0.05$ as statistically significant value. No statistically significant difference in scores was observed among demographic variables.

\section{Discussion}

The present study revealed that the TB patients have poor knowledge regarding their disease. The lack of knowledge was analyzed after determining various components for assessing the knowledge; this is supported by the study which also states the same situation conducted in Malaysia ${ }^{13}$. Contrary to the findings of other study, which showed that the knowledge about tuberculosis among TB patients was quite high ${ }^{17}$.

Significance of demographics was analyzed to estimate knowledge of TB and result showed that there is no significant effect of demographics on study, these demographics includes various variables like age group, gender, ethnicity, locality, marital status, education and income. Contrary to the findings of the study conducted by Agboatwalla et $\mathrm{al}^{14}$ in Turkey, which shows significant effect of majority of demographics on their study.

This study showed that there was very little information present from the TV reason is this majority of patients were from rural area so they are not having a TV this finding is supported by study conducted in Ethiopia ${ }^{11}$. The findings of this study show that main source of information was brochures, posters and other printed materials and it is supported by the study conducted in Pakistan which have the similar findings ${ }^{14}$. 
The cause of the disease is main concern while assessing the knowledge of the disease among patients and knowing the cause can help in decreasing the occurrence of disease, among these causes the lack of knowledge was seen in TB patients. These findings are consistent with the study conducted to assess the knowledge about tuberculosis among newly diagnosed TB patients in India $^{18}$. There is better understanding of symptoms of TB in our study subjects so this can be helpful in controlling TB occurrence and these findings also consistent with study conducted in India, where maximum patients know that cough is the more frequent symptom of $\mathrm{TB}^{18}$. The findings of this study in terms of locality showed that patients from rural area have good knowledge of TB and this is supported by findings similar to study conducted in Lima Peru ${ }^{19}$.

In this study, it was found that knowledge about the BCG vaccination as a preventive measure was very limited and few patients know that there is vaccination available for TB as preventive measure and it is supported by the study conducted in Pakistan ${ }^{15}$. So lack of knowledge about prevention can cause effect on prevalence rate of TB.

Disease condition was assessed either it is cure able or not so the majority of respondents defined TB as a curable disease this was in agreement with a study conducted in Pakistan. After that another parameter about knowledge of treatment duration was analyzed as shown in results so it also shows lack of knowledge among patients and standard treatment was limited so there may be the chances of treatment relapse and MDR TB, this is consistent with the previous studies conducted in Pakistan ${ }^{15}$.

Appropriate knowledge is of prime importance for control and prevention of many diseases and tuberculosis. This study concludes that knowledge about tuberculosis among the patients registered in Fatimah Jinnah hospital \&who visited hospital is low and highlights the importance for planning designing and applying appropriate programs and interventions to propagate the knowledge and information about tuberculosis in the general population. There is need of more studies and research to assess knowledge and understanding about tuberculosis at higher and community basis. This should only be possible with incorporated efforts by government and nongovernmental health organizations, media along with active community participation. In this study, it was found that knowledge about the diagnosis of disease is far better as compared to the knowledge of the cause \& mode of transmission of TB. The reason behind this may be that this is the only knowledge which is provided by health care professionals at the time of diagnosis. If some more attention is given to other issues, including the knowledge regarding cause, mode of transmission may increase which might be helpful in the control of tuberculosis among general population. The results of this study should be interpreted with caution as the study was conducted among patient and not ideally representing the general population.

\section{Conclusion}

Knowledge is a key factor in understanding any particular disease. If the level of knowledge is low in some or all parts of the disease, it will actually affect the patient. It can be concluded that there is a need to raise awareness of TB symptoms, mode of transmission, prevention, diagnosis and treatment of the disease through health education. In this study majority of study subjects had poor knowledge about cause of tuberculosis, its mode of transmission and duration of treatment while knowledge regarding the major symptoms of TB was found better among most of the respondents. It is concluded that as knowledge is a key factor for the prevention and control of TB, it is obvious to plan and apply appropriate health education programs, seminars and interventions regardless to the level of education of population to propagate the knowledge and information about causes, transmission and duration of treatment of tuberculosis in the general population and TB patients to coup with further disease progression in Pakistan.

It is recommended that knowledge is prime factor that affects $\mathrm{TB}$, and proper health education, awareness programs within community should be held to clarify the concepts of patients about cause of disease if they know basic underlying cause there will be more improvement in controlling TB. Another parameter was transmission of disease that also need more efforts to aware patients and population if they know about transmission so there would be less chances of disease propagation and ultimately there would be less chances of disease progression.

\section{References}

1. Ailinger RL, Lasus H, Dear M. Americans' knowledge and perceived risk of tuberculosis. Public Health Nursing 2003;20(3):211-5

2. Emili J, Norman G, Upshur R, Scott F, John K, Schmuck M. Knowledge and practices regarding tuberculosis: a survey of final-year medical students from Canada, India and Uganda. Medical education. 2001;35(6):530-6

3. Jurcev Savicevic A, Popovic-Grle S, Milovac S, Ivcevic I, Vukasovic M, Viali V, et al. Tuberculosis knowledge among 
patients in out-patient settings in Split, Croatia. The International Journal of Tuberculosis and Lung Disease. 2008;12(7):780-5

4. Obuku EA, Meynell C, Kiboss-Kyeyune J, Blankley S, Atuhairwe C, Nabankema E, et al. Socio-demographic determinants and prevalence of Tuberculosis knowledge in three slum populations of Uganda. BMC public health. 2012;12(1):536

5. Seyoum A, Legesse M. Knowledge of tuberculosis (TB) and human immunodeficiency virus (HIV) and perception about provider initiated HIV testing and counselling among TB patients attending health facilities in Harar town, Eastern Ethiopia. BMC public health. 2013;13(1):124

6. Tuberculosis. [Factsheet] WHO: World Health Organization; 2015 [updated October 2015; cited 201530 November]; Available from: http://www.who.int/mediacentre/factsheets/fs 104/en/.

7. Organization WH. Global tuberculosis control: WHO report 2015: World Health Organization; 2015

8. Smith I. Mycobacterium tuberculosis pathogenesis and molecular determinants of virulence. Clinical microbiology reviews. 2003;16(3):463-96.

9. Tubercluosis. 2015 [cited 201530 November]; Available from: http://medicaldictionary.thefreedictionary.com/Tubercluosis

10. DeRiemer K, Daley CL, Reingold AL. Preventing tuberculosis among HIV-infected persons: a survey of physicians' knowledge and practices. Preventive medicine. 1999;28(4):437-44

11. Esmael A, Ali I, Agonafir M, Desale A, Yaregal Z, Desta K. Assessment of patients' knowledge, attitude, and practice regarding pulmonary tuberculosis in eastern Amhara regional state, Ethiopia: cross-sectional study. The American journal of tropical medicine and hygiene. 2013;88(4):785-8

12. Kanjee Z, Catterick K, Moll A, Amico K, Friedland G. Tuberculosis infection control in rural South Africa: survey of knowledge, attitude and practice in hospital staff. Journal of Hospital Infection. 2011;79(4):333-8

13. Liam C, Lim K, Wong C, Tang B. Attitudes and knowledge of newly diagnosed tuberculosis patients regarding the disease, and factors affecting treatment compliance. The International Journal of Tuberculosis and Lung Disease. 1999;3(4):300-9

14. Agboatwalla M, Kazi G, Shah S, Tariq M. Gender perspectives on knowledge and practices regarding tuberculosis in urban and rural areas in Pakistan. 2003

15. Mushtaq MU, Shahid U, Abdullah HM, Saeed A, Omer F, Shad MA, et al. Urban-rural inequities in knowledge, attitudes and practices regarding tuberculosis in two districts of Pakistan's Punjab province. Int J Equity Health. 2011;10(8)

16. Jafarey AM, Iqbal SP, Hassan M. Ethical review in Pakistan: The credibility gap. J Pak Med Assoc. 2012;62(12):1354-7

17. Hoa N, Diwan V, Co N, Thorson A. Knowledge about tuberculosis and its treatment among new pulmonary TB patients in the north and central regions of Vietnam. The International Journal of Tuberculosis and Lung Disease. 2004;8(5):603-8

18. Damor R, Singh M, Jankar D, Rathod S, Gosaliya V. Assessment of knowledge about tuberculosis among newly diagnosed patients registered in District Tuberculosis Center, Bhavnagar, Gujarat. 2012

19. Kiefer EM, Shao T, Carrasquillo O, Nabeta P, Seas C. Knowledge and attitudes of tuberculosis management in San Juan de Lurigancho district of Lima, Peru. The Journal of Infection in Developing Countries. 2009;3(10):783-8 